\title{
Determinants of Satisfaction with Training Process among Final Year Nursing Students at Kenya Medical Training College
}

\author{
Kabanya C ${ }^{1 *}$, Karani $\mathrm{A} \mathrm{K}^{2}$ and Mirie $\mathrm{W}^{3}$ \\ ${ }^{1}$ PhD Student, University of Nairobi, Kenya \\ ${ }^{2}$ Professor, University of Nairobi, Kenya \\ ${ }^{3}$ Senior Lecturer, University of Nairobi, Kenya
}

Received: August 15, 2017; Published: September 07, 2017

*Corresponding author: Kabanya C N, Kenya Medical Training College, University of Nairobi, EMBU, KENYA, Tel: +254-923-60100, Email: ckabanya@kmtc.ac.ke

\begin{abstract}
Purpose: To identify the factors that influenced satisfaction with the training process among the final year nursing students in Kenya Medical Training College.

Method: This was a descriptive correlational study where both quantitative and qualitative data was collected from 300 students using a self-administered questionnaire comprising of closed and open ended questions.

Results: The quality of training was good. $93.6 \%$ of the students were satisfied while $0.7 \%$ was dissatisfied with the teaching and learning process. Results of regression analysis indicated that curriculum and instruction, teaching faculty, teaching learning resources, skills lab training and clinical supervision had a significant influence on teaching and learning process

Conclusion: During the training students acquired relevant skills needed to perform nursing duties such as critical thinking and problem solving skills, effective communication skills and self-confidence, ethical behavior and professional etiquette, emotional maturity and ability to work with other team members.
\end{abstract}

Keywords: Student Satisfaction; Teaching and Learning; Curriculum Instruction; Clinical Supervision

\section{Introduction}

Student satisfaction is defined as meeting or exceeding the student's expectations of campus reality [1]. Although the requirements of nurse training courses are largely fulfilled when the system produces competent nurses and satisfies the standards of the consumers and regulators of health care, students' opinion on their training cannot be ignored if improvements in the quality of training and customer satisfaction are to be achieved [2]. There is a wider acknowledgement that the totality of a student experience of an institution is a useful perspective to adopt in student satisfaction and marketing of the institution [3]. Students in Kenya Medical Training College are regarded as valuable customers and hence their satisfaction with services during training is very important if the College is to remain relevant in the training of health care providers. Student's satisfaction can be an important quality indicator with respect to teaching and learning. This study was done to determine the factors that influenced satisfaction of student nurses with the training process. This will ultimately impact positively on nursing care delivery to patients and clients since satisfied students are more likely to be successful and dedicated to accomplish their goals than unsatisfied students.

Understanding student's level of satisfaction at the end of training programme forms a basis of determining the quality of nursing education given as perceived by the students. Nursing education combines both theory and practical knowledge and skills. Learning depends not only upon how teachers have designed and structured their subjects and courses but also upon how their students perceive and understand this design and structure. When students have a positive attitude towards a certain subject or the subject lecturer, they tend to perform better in that area. The goal of integrating the practical and theoretical knowledge is spelt out in the nursing curricular. This is where students learn theory for a block of four to six weeks that is followed by clinical area placements for a period of six months. Studies done by $[4,5]$ indicated that students were more satisfied with clinical practice than with the theoretical part of nursing program. Consequently [6] argued that despite the quality of education offered, excellence in 
customer service is the most important factor in determining the success of a learning program. Students who expressed satisfaction with training enjoyed their clinical placement; they felt welcomed, well oriented and supported [7]. There are many factors that affect nursing training like; inadequate infrastructure, inefficient use of educational techniques and technologies, and other problems specific to nursing. Advances in health services, changes in the conception of nurse's roles, professional responsibilities and the changing needs and expectations of the customer of health services have made it necessary to initiate quality studies in nursing education and practice in order to improve nursing education and practice [8]. This has a direct impact on the quality of nursing care given to patients and clients.

Effective teaching is multidimensional and no single criterion is sufficient in itself. It is characterized by giving feedback to students, understanding students' problems and the presentation of subjects in an interesting manner. While studying the effectiveness of different teaching behaviors in the clinical environment [4] identified four useful themes. Which include: supportive, evaluative, instructive and preparatory behavior? Support makes students know that they are cared about whereas evaluation gives a feedback on students' areas of performance and point out areas that require improvement. The clinical supervisors/preceptors in Kenyan training hospitals support students in the clinical learning experiences during practice periods undertake clinical teaching, supervise students work so as to ensure the quality of care and assess students' performance during these periods.

Research studies done by $[9,10]$ on student nurses satisfaction with their training revealed various factors that influence their satisfaction. The module teams displayed good knowledge of the subject and that the references needed for the module were available in the library, According to [4] students were more satisfied with the challenging behavior of the clinical teacher than the nurse supervisor. They were also more satisfied with clinical practice than theoretical part of the nursing program [3]. Some students indicated that they were satisfied with touching people's lives, impacting someone else's life and changing people's lives for better. Learning to save lives was the most satisfying factor and the students anticipated being called to provide life saving measures regularly in their career [2]. In a research study done [11] students expressed excitement with how the application of nursing knowledge and skills directly impacted patients' health and wellbeing. They were delighted in seeing changes in people's condition resulting from their interventions.

Some students expressed that pursuit of nursing education and being a nurse was their lifelong dream with many expressing their sense of pride as nursing students who would eventually become practicing nurses [11]. These students received respect from family members, acquaintances and peers after choosing nursing as a career. In other studies, $[9,12]$, students were found to have high satisfaction with nursing curriculum and instructions, accessibility of instructors and with members of the faculty of nursing who were concerned to protect students from hospital hazards. Studies by $[13,14]$ revealed that certain factors exert positive and significant influences on student satisfaction. These factors include, student background characteristics, participation in the community, access to and use of college facilities and services, faculty style of instruction, academic and social integration, learning activities, courses, quality and usefulness of education. The students were also satisfied with their training in that they were guaranteed of a job anywhere in the world.

\section{Objective of the Study}

The aim of the study was to identify the determinants of satisfaction with the training process among final year nursing students at Kenya Medical Training College.

\section{Study variables}

Independent variables: Faculty staff, curriculum and content delivery, learning environment (classrooms, library, skills laboratory, clinical placements areas and other support services).

Dependent variable: Perceived level of satisfaction

\section{Methods}

The study used a descriptive co relational design which examined the relationship between the independent and dependent variables identified in the study. Cluster sampling was done where a cluster comprising of six campuses of Kenya Medical Training College was randomly sampled. All students who gave informed consent to participate in the study filled the questionnaire. This study was approved by University of Nairobi /Kenyatta National Hospital Ethical Review Committee. A structured questionnaire comprising of open and closed ended questions was used to collect data from the respondents. The questionnaires were hand delivered and distributed to the respondents in a classroom in the identified campuses and collected immediately they were filled. The return rate was $100 \%$.

Data was processed stepwise and involved data validation, data cleaning, data coding and entry into Statistical Package for Social Sciences (SPSS) version 20.0 in order to generate quantitative and qualitative data. Descriptive statistics were computed to generate means, percentages, ranges and standard deviation and the results presented in form of frequency tables, bar graphs and narration. Inferential statistics were generated using Pearson's coefficient and Chi-square test in order to determine the relationship between student factors and institutional factors that influence level of satisfaction with training. The level of significance was set at $\mathrm{P}<0.05$. Logistic regression model was also used to analyze the predictors of satisfaction.

\section{Results}

\section{Gender influence on students' satisfaction on teaching and learning process}

The gender of the students did not affect their overall satisfaction with the teaching and learning process of nursing $(\chi 2=$ $2.110, \mathrm{P}=0.550$ ). Among the male students, $71.2 \%$ were satisfied with the teaching and learning programme whereas $75.4 \%$ of the female students were satisfied (Table 1). 
Table 1: Gender of students' and the level of satisfaction with the teaching/learning process.

\begin{tabular}{|c|c|c|c|c|c|c|c|}
\hline & & & \multicolumn{4}{|c|}{ Overall satisfaction with the teaching and learning process of the nursing program } & \multirow{2}{*}{ Total } \\
\hline & & & Not satisfied & Somehow satisfied & Satisfied & Extremely satisfied & \\
\hline \multirow{4}{*}{ Gender } & \multirow{2}{*}{ Male } & $\mathrm{N}$ & 0 & 30 & 68 & 6 & 104 \\
\hline & & $\%$ & $.0 \%$ & $28.8 \%$ & $65.4 \%$ & $5.8 \%$ & $100.0 \%$ \\
\hline & \multirow{2}{*}{ Female } & $\mathrm{N}$ & 2 & 42 & 123 & 12 & 179 \\
\hline & & $\%$ & $1.1 \%$ & $23.5 \%$ & $68.7 \%$ & $6.7 \%$ & $100.0 \%$ \\
\hline \multirow{2}{*}{ Total } & $\mathrm{N}$ & 2 & 72 & 191 & 18 & 283 & \\
\hline & $\%$ & $.7 \%$ & $25.4 \%$ & $67.5 \%$ & $6.4 \%$ & $100.0 \%$ & \\
\hline
\end{tabular}

Learners' involvement in extra-curriculum activities in the college

While in college, $48.3 \%$ of the learners were involved in extra-curriculum activities. These activities include; Sports like football, rugby, volleyball, handball, basketball, hockey, lawn tennis, table tennis, scrabble, badminton and athletics. Other activities like charitable work for example, visiting prisoners and children homes, participating in outreach services organized by the hospitals, participating in hospital meetings and also setting the immunization groups. They were also involved in clubs like counseling. The extent to which the learners' participation in extracurriculum activities contributed to their overall satisfaction with college experience was analyzed. $13.0 \%$ of the learners felt that the activities contributed extremely to their overall satisfaction, $14.3 \%$ stated that it slightly contributed, 32.75 stated participation in the activities moderately contributed to their satisfaction while $40 \%$ of the learners felt that it did not contribute to their overall satisfaction at all (Figure 1). The extent to which the learners participated in the extra-curriculum activities had significant influence $(\mathrm{r}=0.143, \mathrm{P}=$ 0.026 ) on their satisfaction with the teaching and learning process of the nursing program. Students who felt that their participation in the extra-curriculum activities contributed to their satisfaction with college experience were satisfied with the overall teaching and learning process.

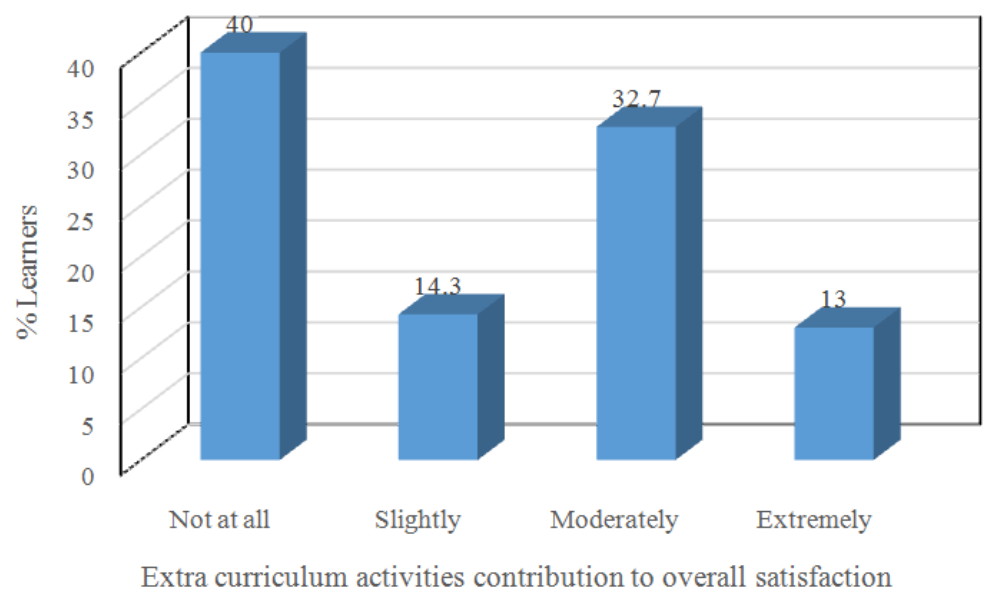

Figure 1: Extent to which students' participation in extra-curriculum activities contributed to overall satisfaction with college experience.

\section{Correlation analysis on the clinical supervision factors and the students' satisfaction with teaching and learning process}

Students who were satisfied with the commitment by the clinical supervisor were significantly satisfied with teaching and learning process of the nursing programme $(\mathrm{r}=0.203, \mathrm{P}=0.001)$. Similar significant relationship was recorded in other clinical supervision items tested $(\mathrm{P}<0.05)$ except on availability of the hospital equipment and supplies $(r=0.084, \mathrm{P}=0.160)$.

\section{Overall satisfaction with the teaching and learning process of the nursing program}

The students overall satisfaction with the teaching and learning process was established. The result revealed that, besides the other minor issues that rose in the colleges, $6.0 \%$ of the students were extremely satisfied with the learning process, $63.7 \%$ of the students were satisfied while $24 \%$ were somehow satisfied. However, $0.7 \%$ of the students were not satisfied with the teaching/ learning process in the colleges (Figure 2). Correlation analysis on the students overall rating and the students satisfaction with teaching and learning process showed that, there was a significant relationship between the overall rating of the quality of training ( $\mathrm{r}$ $=0.374)$, adequacy of training facilities $(r=0.224)$, acquisition of relevant knowledge and competencies $(r=0.193)$, extra-curriculum activities ( $r=0.215$ ) with the students' overall satisfaction with the teaching and learning process of the nursing programme. Those who indicated the ratings were good were the students who were satisfied with the teaching process hence the positive correlation values (Table 2). 


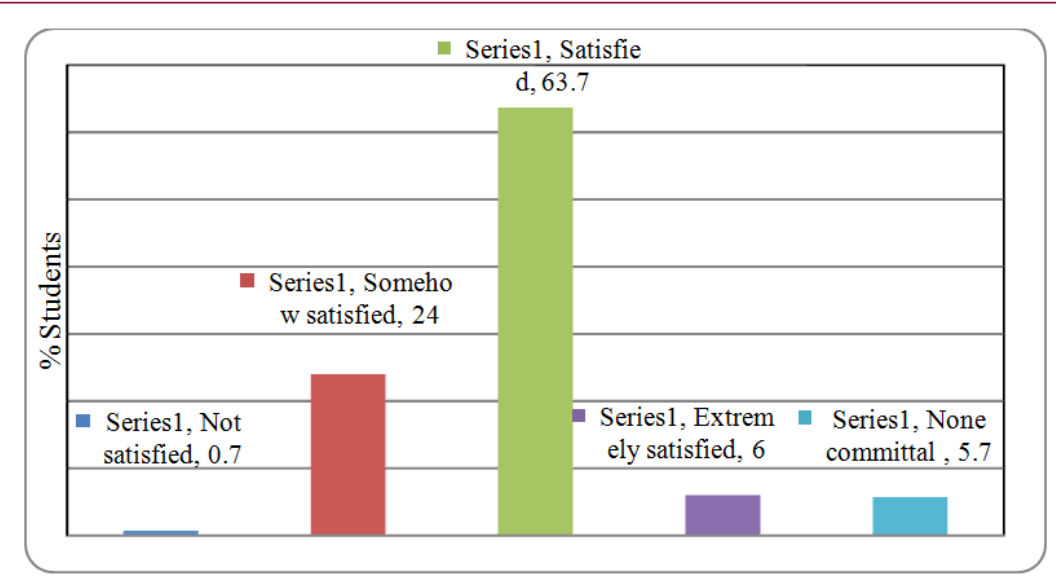

Figure 2: Overall satisfaction of the students with the teaching and learning process.

Table 2: Correlation matrix of the students overall rating with students' satisfaction with teaching and learning process.

\begin{tabular}{|c|c|c|c|c|c|c|c|}
\hline & & 1 & 2 & 3 & 4 & 5 & 6 \\
\hline \multirow{2}{*}{ Overall satisfaction with the teaching and learning process } & r-value & 1 & $.374(* *)$ & $.224(* *)$ & $.234\left(^{* *}\right)$ & $.193\left(^{* *}\right)$ & $.215(* *)$ \\
\hline & P-value & . & .000 & .000 & .000 & .001 & .000 \\
\hline \multirow{2}{*}{ Overall quality } & r-value & $.374(* *)$ & 1 & $\left..459{ }^{* *}\right)$ & $.459\left(^{* *}\right)$ & $.382(* *)$ & $.249(* *)$ \\
\hline & P-value & .000 & . & .000 & .000 & .000 & .000 \\
\hline \multirow{2}{*}{ adequacy of the training facilities } & r-value & $.224(* *)$ & $.459\left(^{* *}\right)$ & 1 & $.550\left(^{* *}\right)$ & $.438\left(^{* *}\right)$ & $.398(* *)$ \\
\hline & P-value & .000 & .000 & . & .000 & .000 & .000 \\
\hline \multirow{2}{*}{ trainers ability } & r-value & $.234\left(^{* *}\right)$ & $.459\left(^{* *}\right)$ & $.550\left(^{* *}\right)$ & 1 & $.623\left(^{* *}\right)$ & $.399\left(^{* *}\right)$ \\
\hline & P-value & .000 & .000 & .000 & . & .000 & .000 \\
\hline \multirow{2}{*}{ acquisition of relevant knowledge and competencies } & r-value & $.193(* *)$ & $.382(* *)$ & $.438(* *)$ & $.623(* *)$ & 1 & $.324(* *)$ \\
\hline & P-value & .001 & .000 & .000 & .000 & . & .000 \\
\hline \multirow{3}{*}{ extra-curricular activities e.g sports, clubs etc. } & r-value & $.215\left(^{* *}\right)$ & $.249(* *)$ & $.398(* *)$ & $.399\left(^{* *}\right)$ & $.324\left({ }^{* *}\right)$ & 1 \\
\hline & P-value & .000 & .000 & .000 & .000 & .000 & . \\
\hline & $\mathrm{N}$ & 280 & 278 & 278 & 279 & 280 & 282 \\
\hline
\end{tabular}

** Correlation is significant at the 0.01 level (2-tailed).

1. overall satisfaction with the teaching and learning process of the nursing program; 2 . Overall quality; 3 . adequacy of the training facilities; 4. Trainers ability; 5. Acquisition of relevant knowledge and competencies; 6- extra-curricular activities e.g sports, clubs etc.

\section{Discussion}

The student factors that influenced satisfaction with teaching and learning in nursing training were identified from the study. The learners' participation in extra curriculum activities such as sports had significant influence on their satisfaction in the learning process. Exercise and sports helps in relaxation of the mind and body thereby preventing mental fatigue and making life enjoyable. Similar findings were reported by [15] who argued that campus life outside the classroom was important to students' satisfaction as educational experience The orientation the students received concerning the expectations of the course, the provision of course outlines, organization and flow of course content, assessing methods and examination grading system all contributed to the students satisfaction with the teaching learning process. The course assessment methods have been found to be a significant factor in overall students' satisfaction in a number of studies [15-17].

Teaching faculty members significantly influenced satisfaction of nursing students with teaching learning process positively
The relationship between the faculty and students is of extreme importance for planning and implementation of learning activities. This is where the students are involved in decision making in areas concerning their leaning. Faculty performance and students experience are important variables that influenced students overall satisfaction. The students who received effective meaningful academic coaching felt more satisfied. These findings concur with a study by [18]. In the skills laboratory the students were happy and satisfied that the learning objectives were available and the students knew what their expected behavior was during the training. Training manuals were available for their use and the committed lecturers used the training manuals to teach the students through demonstrations of procedures and allowed them time for return demonstrations. Individualized coaching was considered and assessments in the skills lab were also rated as objective. The student nurses reported satisfaction with skills laboratory training where there was concurrence of theory and practical. Similar findings were cited in a previous study by [19]. 
The clinical supervisors and mentors are instrumental in clinical teaching, mentorship and role modeling. They give Individualized coaching, co-assess and give feedback to the students while in the clinical areas. Faculty team also follows up the students in clinical areas and receives reports about the student performance in the clinical areas. This study showed that students were satisfied with commitment of clinical supervisor's, availability of clinical cases (patients and clients), and objectivity of clinical assessments. Students who were satisfied with commitment of clinical supervision were significantly satisfied with teaching and learning process and similar significant relationship with teaching and learning process was recorded with supervision of items tested in the study these findings concur with those of previous studies $[7,10]$.

The study revealed that students were satisfied with the learning environment. That is the classrooms were conducive with adequate lighting and ventilation, library facilities, skills laboratory and computer laboratory were available. However they were more satisfied with availability of teaching/learning resources than the infrastructure. Those not satisfied cited congestion in these facilities and recommended expansion of the infrastructure to accommodate the growing population of college students. The students' satisfaction was found to be positively related to all items comprising the learning environment in the school of nursing. Similar findings were reported by $[9,20]$. The final year student nurses were happy with the overall training. They felt well prepared having acquired relevant skills needed for the job such as critical thinking and problem solving skills, effective communication skills and self-confidence, ethical behavior and professional etiquette, emotional maturity and ability to work with other team members. The final year nursing students were satisfied that there were prospects of employment. These findings are similar to those of previous studies $[9,12]$.

In the overall rating the students felt that the quality of training was good. $93.6 \%$ of the students were satisfied with the teaching and learning process while 5.7\% were non-committal. However, only $0.7 \%$ of the final year nursing students were dissatisfied with the training process. Further the results of regression analysis indicated that the following factors had a significant influence on teaching and learning process: curriculum and instruction, teaching faculty, teaching learning resources, skills lab training, clinical supervision, other support services and involvement in extra curriculum activities like sports and clubs. It can be implied that the satisfaction of the students with these tested factors is what contributed to the $93.6 \%$ of final year nursing students expressing satisfaction with teaching and learning process.

\section{Conclusion}

The teacher based factors that influenced final year nursing students' satisfaction with teaching and learning process were curriculum instruction method, and the relationship between faculty members and their students. The environmental factors that influenced student nurses level of satisfaction were the teaching and learning resources and other related support services. Overall only $6 \%$ of the students were extremely satisfied with the teaching and learning process, $87.7 \%$ of them had some level of satisfaction while $0.7 \%$ was dissatisfied. However, $5.7 \%$ of the respondents were non- committal.

\section{Recommendation}

There is need to carry out further research to determine whether satisfaction with the teaching and learning process translates into better performance in nursing practice after graduation.

\section{References}

1. Boylston MT, Jackson C (2008) Adult student satisfaction in an Accelerated RN-to-BSN program: A follow-up study. J prof Nurs 24(5): 285-295.

2. Mimura C (2009) What motivates people to enter professional nursing? International Journal of Nursing studies. 46(5): 603-605.

3. Alos SB, Caranto LC, David JTD (2015) Factors affecting the Academic performance of the student nurses of BSU. International Journal of Nursing Science 5 (2): 60-65.

4. Espeland V, Indrehus $O$ (2003) Evaluation of students' satisfaction with nursing education in Norway. Journal of Advanced Nursing 42(3): 226236.

5. Kyrkjebo JM, Mekki TE, Hanestad BR (2001) Short report. Nursing education in Norway. Journal of Advanced Nursing 38: 296-302.

6. Hadfield J (2003) Recruiting and retaining adult students. New direction for student services 102: $17-26$.

7. Happell B (2008) Clinical experience in mental health nursing: Determining satisfaction and the influential factors. Nurse Education Today. 28(7): 849-855.

8. Bayka U, Sokmen S, Korkmaz S, Akgun E (2005) Determining Student Satisfaction in Nursing College. Nurse Education Today 25: 255-262.

9. Lo C C (2010) How student satisfaction factors affect perceived learning. Journal of the Scholarship of Teaching and Learning 10(1): 47 - 54.

10. Tiwaken SU, Caranto LC, David JJT (2015) The Real World: Lived Experiences of Student Nurses during clinical practice. International Journal of Nursing Science. 5(2): 66-75.

11. Linda N, Buerhans PI, Donelan K, McCloskey, Dittus R (2005) Nursing students assess Nursing Education. Journal of Professional Nursing 21(3): 150-158.

12. Jaradeen N, Jaradat R, Safi AA, Tarawneh FA (2012) Student's satisfaction with nursing program. Bahrain Medical Bulletin 34(1).

13. Elliot KM, Shin D (2002) Student satisfaction: an alternative approach to assessing this important concept. Nurse Education Today 24(2): 197209.

14. Liegler RM (1997) Predicting students' satisfaction in Baccalaureate nursing program testing a causal model. Journal of Nursing Education 36(8): 357-364.

15. Tessema MT, Ready K, Yu WW (2012) Factors affecting college satisfaction with major curriculum: Evidence from nine years of data. International Journal of Humanities and Social Science 2(2): 34.

16. Sampson SF, Leonard J, Ballenger JW, Coleman JC (2010) Students' satisfaction of online courses for education leadership. Online journal of distance learning administration 8(3).

17. Elliot KM (2002) Key determinants of student satisfaction. Journal of college students' retention 4 (3): 271-279.

18. Ziaee V, Ahmadinejab Z, Morravedji AR, (2004) An evaluation on medical students satisfaction with clinical education and its effective factors. Med Educ online 9(1): 4365. 
19. Lee CY, White B, Hong YM (2009) Comparison of the clinical practice satisfaction of nursing students in Korea and the USA Nurs Heal Sci 11(1): 10-16.
20. Papastavrou E, Dimitriadou M, Tsangari H, Andreou C (2016) Nursing students satisfaction of the clinical learning environment: a research study. BMC Nursing 15: 44. 